\title{
EMG Silent Periods in Immediate Complete Denture Patients: A Longitudinal Study
}

\author{
W. D. MCCALL JR., * ANTJE TALLGREN, ** and M. M. ASH, JR. \\ Department of Occlusion, Dental Research Institute, School of Dentistry, University of Michigan, \\ Ann Arbor, Michigan 48109
}

Jaw muscle silent periods in response to chin taps were recorded from immediate complete denture patients before extraction of a residual anterior dentition, after insertion of the dentures, and three and six months after insertion. After three months' use of the dentures, the mean EMG silent period duration was significantly increased compared to the pre-extraction stage.

J Dent Res 58(12):2353-2359, December 1979

\section{Introduction.}

The electromyographic (EMG) silent period has been defined" 1 as "a relative or absolute decrease of activity in the midst of an otherwise sustained contraction." EMG silent periods in a dental context in relation to chewing and biting, ${ }^{2-4}$ and in connection with occlusion, ${ }^{5}$ were first noted more than a decade ago. Later, it was observed 6 and confirmed $^{7-11}$ that a group of TMJ dysfunction patients had a prolonged mean silent period duration when compared to a group of asymptomatic subjects. Thus, the possibility arose of using the silent period duration as a quantitative adjunct to clinical diagnosis. It therefore became of interest to investigate this phenomenon in other dental groups.

Silent periods have been reported also in edentulous subjects wearing complete dentures. Matthews and Yemm 12 found silent periods in the masseter muscles in full denture wearers during voluntary tapping of the artificial teeth, and concluded that silent periods in masticatory muscles are not necessarily dependent on stimulation

Received for publication July 31,1978

Accepted for publication December 28, 1978

Supported by USPHS Grant DE 02731

${ }^{*}$ Present Address: Department of Oral Medicine, School of Dentistry, State University of New York at Buffalo, Buffalo, New York 14214.

**Present Address: Institute of Dentistry, University of Turku, Turku 52, Finland. of periodontal mechanoreceptors. Other authors have reported silent periods in full denture wearers during voluntary tapping $13,14,15$ and chewing. 15,16

The above-mentioned investigations on denture patients have all used voluntary movements to elicit the silent periods and not taps to the chin during a sustained clench. The methodological variables associated with chin tap silent periods have been analyzed in dentate subjects. ${ }^{8,10,17-19}$ These latter investigations suggest that the silent period duration does not differ among the elevator muscles and is unaffected by tap direction, tap force, degree of jaw opening, order of tap in sequence, bite force when the bite is bilateral, and the lapse of time.

The silent period duration in response to voluntary tapping, on the other hand, may depend crucially on the occlusion. It has been shown 20 that multiple tooth taps can cause prolonged silent periods. It has also been shown by Watt et al. ${ }^{21}$ that changes in the frequency of silent periods occur in subjects with occlusal prematurities. Thus, the dynamics of achieving intercuspation may be expected to influence the silent period duration. No studies, however, have been reported on possible changes in duration of EMG silent periods due to loss of teeth and insertion of complete dentures.

The purpose of the present longitudinal investigation was to examine the pattern and duration of EMG silent periods from some masticatory muscles in response to a chin tap during a forceful clench in a sample of partially edentulous subjects and, subsequently, after insertion and wearing of immediate upper and lower complete dentures.

Materials and methods.

Subjects. - The original sample consisted 
of 18 subjects, 8 women and 10 men, assigned for immediate complete denture treatment at the University of Michigan School of Dentistry. The age of the patients ranged from 24 to 69 years with a mean age of 50.4 years. For sixteen of these patients, follow-up examinations were made during one-half year of denture wear. None of the patients reported signs or symptoms of TMJ dysfunction. Informed consent was obtained from each subject.

Clinical protocol. - Electromyographic recordings of jaw muscle activity were obtained at the following observation stages:

I. prior to extraction of the residual dentition;

II. after insertion of immediate complete upper and lower dentures; on the average 3 weeks after surgery and insertion when the patients felt comfortable with the dentures and did not complain of sore spots;

III. 3 months after denture insertion; and

IV. 6 months after insertion.

At each observation stage, a series of EMG procedures such as postural position, tapping, and clenching were recorded,2 2 in addition to taps on the chin for eliciting of silent periods. Lateral cephalometric radiographs in centric occlusion and postural position were also taken at each session.

Prior to the first recording, the subjects, as a rule, had had all their molars and second premolars extracted; some patients were also missing the first premolars. The posterior teeth used for the complete dentures were zero degree $31 \mathrm{~mm}$ acrylic resin teeth, and were set to a flat plane without compensating curves and without protrusive balance.

Electromyographic recordings. - The muscles studied were the right and left anterior temporal muscles, the right and left masseter muscles, and the anterior digastric, defined in this study as the suprahyoid muscle group. Bipolar surface electrodes with an inter-electrode distance of $2 \mathrm{~cm}$ were placed by palpation of the muscles in the main direction of the fibers, and care was taken that for each individual the electrode placement, as far as possible, was identical at different sessions. During the electromyographic recording, the patient was seated in a dental chair in a shielded room in an upright but relaxed position with the head unsupported. To elicit the silent periods, the patient was instructed to bite the teeth together in habitual occlusion as forcefully as possible, while 5 taps were delivered at a $45^{\circ}$ angle to the chin with a reflex hammer and short dowel. ${ }^{8}$ The taps were delivered at about one-second intervals. After amplification of the signals, the EMG traces were recorded on analog FM magnetic tape at $30 \mathrm{in} / \mathrm{sec}$ for later replay in time expansion at $7.5 \mathrm{in} / \mathrm{sec}$. On replay, the paper speed was $50 \mathrm{~mm} / \mathrm{sec}$ giving a conversion factor of $5 \mathrm{~ms} / \mathrm{mm}$.

On the EMG traces the silent period was defined as beginning at the last significant peak before the motor pause and ending at the first peak of the ongoing activity after the period of inhibition (Fig. 1 A). The measurements were made manually with calipers to the nearest $0.1 \mathrm{~mm}$, which corresponds to $0.5 \mathrm{~ms}$. For each muscle the durations of the five silent periods were averaged.

Statistical analyses. - To test whether the unmeasurable silent periods were randomly distributed over the muscles and the sessions, Cochran's $Q$ test was used. ${ }^{23}$ If none, one, or two silent periods were missing, a number one was assigned; if three, four, or five silent periods were missing, a zero was assigned.

To test whether the number of double silent periods observed differed among the sessions, they were counted and the Chi square test used. 23

To test whether the mean silent period durations among muscles within each session differed, a one-way analysis of variance for repeated measures was used. ${ }^{24}$ If the Hartley Fmax test revealed significant differences in variances, the Friedman two-way analysis of variance by ranks was used instead. ${ }^{23}$

To test whether the mean silent period durations differed among sessions, the same procedure as in the preceding paragraph was followed. If a significant difference was found using analysis of variance, it was pursued at the pair level using the Newman-Keuls procedure to avoid the inflation of the alpha level inherent in multiple t-tests.

\section{Results.}

For the subjects studied, five taps on 
A

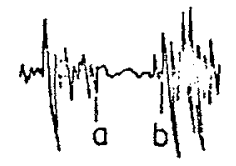

B

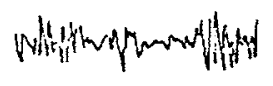

$50 \mathrm{~ms}$

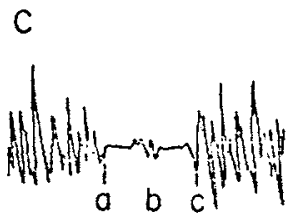

D

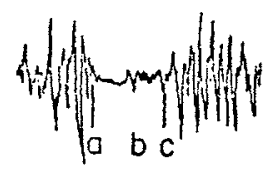

Fig. 1 - EMG traces. A. Typical silent period. The duration was measured from a to $b$. B. Unmeasurable silent period. Onset or end of inhibition was indistinct in about $25 \%$ of the silent periods. C. Double silent period. Medial activity, labeled $b$, was seen in about $15 \%$ of the silent periods. Duration was measured from a to $c$. $D$. Depressed activity. Lower level activity, $b$ to $c$, was sometimes observed at the end of the silent period. The duration was measured from a to $\mathrm{c}$.

the chin were delivered at each of the four sessions and EMG silent periods were observed from each of the four jaw closing muscles. On the other hand, in no instances was a clearly discernible silent period observed in the traces from the suprahyoid muscle group.

Missing data. - In the follow-up investigation, up to one-half year of denture wear, a combination of discontinued participation, non-attendance at a single session, omitted silent period recording, and technical difficulties reduced the sample size at the different observation stages. For 10 subjects complete silent period recordings from all four sessions were available. A larger number of subjects was available for comparison of silent period data between pairs of sessions.

Unmeasurable silent periods. -- For the ten patients recorded at all stages, a total of 800 silent periods from the right and left anterior temporal and masseter muscles were possible. We found 602 silent periods which were distinct and measurable and 198 or about $25 \%$ which could not be measured. The unmeasurable silent periods (Fig. 1B) were not a result of line frequency interference, motion artifact, poor tape quality, or any

other technical difficulty that could be identified.

Using the Cochran Q-test, no statistically significant differences in frequency of missing silent periods were observed among the muscles or among the sessions.

Patterns. - Regarding the pattern of the silent periods in jaw closing muscles, some deviations were noted from the classic pattern illustrated in Fig. 1A. Double silent periods (Fig. 1C) were observed in some instances. These were defined as a silent period with a slight burst of electrical activity in the midst of the inhibition.

Since the double silent periods were included in the measurements, their distribution among sessions was determined. The frequency was $18 \%$ (65 of 362 ) in session I, $14.3 \%$ (29 of 203 ) in session II, $14.4 \%$ (31 of 216) in session III, and $8.7 \%$ (15 of $172)$ in session IV. The average percentage for the whole observation period was $14.7 \%$. The Chi square test failed to show any significant differences in frequency of double silent periods among the four sessions.

In some instances depressed activity was also seen (Fig. 1D). In measuring the silent period duration, the depressed activity, if any, was included in the measurement.

Comparison among muscles. - The silent period durations from the four jaw closing muscles were compared and no significant differences in mean duration were found among the four muscles examined. This result held in each of the four sessions. In session II, three weeks after surgery and denture insertion, the variances were unequal (Hartley Test, $p<.05$ ), so the non-parametric Friedman two-way analysis of variance by ranks was used.

Comparison among sessions. -. Since the differences in mean silent period duration among the four jaw closing muscles were not significant, the data for each subject in each session were pooled. The descriptive silent period data from the ten patients for whom complete data were available from all four sessions are given in Table 1. Analysis of variance for repeated measures showed that a significant difference in mean duration $(.01<\mathrm{p}<.05)$ existed among the sessions. The Newman-Keuls test was utilized for comparison between pairs of means (Table II). The mean silent period duration at the pre-extraction stage (I), 
TABLE I

POOLED SILENT PERIOD DURATIONS (ms) FROM JAW CLOSING MUSCLES AT THE DIFFERENT SESSIONS

\begin{tabular}{lccccc}
\hline \hline Session & $\mathrm{N}$ & Min & Max & Mean & S. D. \\
\hline I & 10 & 27.10 & 65.64 & 39.22 & 12.97 \\
II & 10 & 22.47 & 59.90 & 43.13 & 12.61 \\
III & 10 & 29.71 & 93.19 & 53.38 & 18.83 \\
IV & 10 & 28.83 & 78.10 & 45.53 & 14.42 \\
\hline
\end{tabular}

when the patients occluded on their remaining anterior dentition, was $39.2 \mathrm{~ms}$. Three weeks after insertion of the immediate complete dentures (stage II), the mean duration was slightly higher at $43.1 \mathrm{~ms}$ but did not reach statistical significance. After three months of denture wear (stage III), the silent period duration (mean $53.4 \mathrm{~ms}$ ) showed a significant increase as compared to the pre-extraction stage $(.01<p<.05)$ but not compared to stage II. At six months after insertion (stage IV), a decrease to a mean of $45.5 \mathrm{~ms}$ was noted, but the differences between stage IV and the other stages were not statistically significant. Plots of individual means over sessions were examined but did not alter the impression gained from session means.

A further comparison of the mean silent period durations between pairs of sessions was made by utilizing all available data from the different pairs of sessions. Some increase in the number of subjects was achieved by this technique. The results are shown in Table II. The prolongation of the mean silent period duration at session III was again observed. However, for the 12 subjects, a significant increase was observed between stages I and II $(\mathrm{p}<.02)$, whereas the increase between stages I and III for the
14 subjects did not prove to be statistically significant. The different results of the two tests are most likely related to the difference in number of subjects but underscore the increased duration at stage III.

\section{Discussion.}

In the present longitudinal investigation of complete denture patients, no silent periods were observable in the EMG traces from the suprahyoid muscle group. This finding is in accordance with previous observations of EMG silent periods in dentate subjects.

The pattern of the silent periods in the jaw closing muscles observed in the present sample displayed some deviations from the usual pattern. Thus, it was found that a large fraction of the silent periods were unmeasurable. Experience from previous studies of dentate individuals ${ }^{8-11}$ shows that the silent period is seldom unmeasurable in jaw closing muscles. Yet such a result occurred in nearly $25 \%$ of the silent periods in these denture patients. The study by Watt et al. ${ }^{2} 1$ showed that in subjects with unstable occlusal contacts, as classified by gnathosonogram, silent periods were absent some four times as often as in subjects with stable occlusal contacts.

Another deviation from the usual pattern observed in the present sample was that a large percentage of the silent periods, on the average $15 \%$, were double silent periods. Such patterns were observed both at the partially edentulous stage and at the denture stages, and no significant differences in frequency of the double

TABLE II

COMPARISONS OF MEAN PERIOD DURATIONS (ms) BETWEEN PAIRS OF SESSIONS.

\begin{tabular}{lccccccccc}
\hline \multirow{2}{*}{$\begin{array}{l}\text { Session } \\
\text { pair }\end{array}$} & \multicolumn{3}{c}{ Newman-Keuls test } & \multicolumn{7}{c}{ Paired t-test } \\
\cline { 2 - 10 } & $\mathrm{N}$ & Mean & Mean & Sig. & $\mathrm{N}$ & Mean & Mean & $\mathrm{t}$ & Sig. \\
\hline I-II & 10 & 39.2 & 43.1 & N.S. & 15 & 41.2 & 42.6 & 0.45 & N.S. \\
I-III & 10 & 39.2 & 53.4 & p $<.05$ & 14 & 42.5 & 52.6 & 1.94 & N.S. \\
I-IV & 10 & 39.2 & 45.5 & N.S. & 13 & 40.0 & 44.5 & 1.26 & N.S. \\
II-III & 10 & 43.1 & 53.4 & N.S. & 12 & 42.8 & 53.3 & 2.72 & p $<.05$ \\
II-IV & 10 & 43.1 & 45.5 & N.S. & 12 & 41.6 & 41.9 & 0.08 & N.S. \\
III-IV & 10 & 53.4 & 45.5 & N.S. & 12 & 50.4 & 42.6 & 1.72 & N.S. \\
\hline
\end{tabular}


silent periods among muscles or among stages were observed.

These patterns of silent periods observed in the denture patients cause difficulties in examining individual silent periods and point to the need for automated measurement. Attempts to do this to individual silent periods 5-27 have not been very successful; the computer averaging technique $12,28,29$ seems to be indicated, or perhaps another measuring technique. ${ }^{30}$

Some previous studies by other authors have reported the occurrence of double silent periods in masticatory muscles. Bratzlavsky ${ }^{31}$ reported second reflex inhibitions in the jaw closing muscles following strong electrical stimulation of perioral skin and intraoral mucosa, and considered them to be of a protective nature. $Y u$, Schmitt, and Sessle ${ }^{32}$ observed second inhibitory periods in the masseter muscle upon noxious extraoral electrical stimulation of the upper lip and also by intraoral stimulation. Widmalm and Hedegard, 33 in their recordings of jaw jerk during sustained contraction of jaw elevators from young individuals with acute TMJ symptoms, found double silent periods in 7 out of 14 subjects. In some cases the early and late silent periods merged into a long period with a duration of about 50-60 ms. In healthy subjects, on the other hand, double silent periods were seldom noted. In evaluating the present findings of unmeasurable and double silent periods, one factor to be considered is the unstable occlusal conditions in these denture wearers. Moreover, it is possible that the present method of obtaining the silent periods by tapping on the chin during maximal clench is less than optimal for use with complete denture wearers.

The comparisons of the mean silent period durations among the four stages of observation revealed no significant changes between the pre-extraction stage and the post-insertion stage recorded some three weeks after insertion of the immediate complete dentures. On the other hand, after three months of denture wear the silent period duration showed a significant increase compared to the pre-extraction stage. At the six-month stage of denture wear a decrease in mean silent period duration was noted, but the difference was not significant.
In speculating on the mechanism generating the silent periods in the present sample, it is interesting to note that no significant changes in duration or pattern of the silent periods were observed between the initial stage, when the patients occluded on a residual anterior dentition with presumably intact periodontal ligaments, and the postinsertion stage, when they had used the immediate full dentures for a period of some weeks. Moreover, previous observations on the jaw muscle activity in these subjects during maximal clench at the two stages revealed a significant decrease in mean voltage at the post-insertion stage. ${ }^{34}$ Thus, neither the loss of input from periodontal receptors, nor the decrease in muscle activity in biting, noted upon denture insertion, seemed to have had a decisive effect on the duration and pattern of silent periods observed at the first of the two stages. The present findings confirm the demonstration of Matthews and Yemm, ${ }^{12}$ that receptors in the periodontal ligaments are not a prerequisite for silent periods in jaw closing muscles.

Regarding the significant increase in silent period duration at the 3 -month stage of denture wear, clinical and cephalometric observations on the present subjects ${ }^{35}$ revealed that this stage was characterized by loosening of the dentures due to alveolar ridge resorption, and resultant marked changes in mandibular position and occlusal relationships of the dentures: a forwardupward rotation of the mandible with increased mandibular prognathism, and a decreased overjet or even anterior crossbite. The increase in silent period duration observed at this stage was perhaps in some way related to these factors.

At the half-year stage of denture wear, the mean silent period duration showed a decrease toward the post-insertion level, but the reduction from the three-month stage was not statistically significant. Between the three- and six-month stages the rate of alveolar resorption and resulting changes in jaw and occlusal relationships were markedly less than during the first months of denture wear. Also, the dentures had been relined during this period for about half the subjects, which improved the occlusal conditions. The observed tendency to a decrease in silent period duration may have had some connection with the above- 
mentioned factors.

Although the changes in silent period duration observed in the present sample are interpreted to be associated with the changes in oral and occlusal conditions related to the wearing of the complete dentures, other factors such as the effect of advanced age on the functional ability of the masticatory system ${ }^{14}$ cannot be excluded.

\section{Conclusions.}

The EMG silent period duration in some masticatory muscles was investigated in a sample of partially edentulous subjects before final extractions and after insertion and wearing of immediate full dentures. The study agrees with results of previous studies that receptors in the periodontal ligaments are not a prerequisite for silent periods in jaw closing muscles.

The patterns of the silent periods exhibited some deviations from classical patterns. In this study of denture patients, nearly $25 \%$ of the silent periods were missing or unmeasurable and, on the average, $15 \%$ were double silent periods.

\section{REFERENCES}

1. SHAHANI, B. T. and YOUNG, R. R.: Studies of the Normal Human Silent Period, in J. E. Desmedt (ed.), New Developments in Electromyography and Clinical Neurophysiology, Vol. 3. Basel: S. Karger, 1973.

2. JARABAK, J. R.: Adaptability of Temporal and Masseter Muscle: An Electromyographic Study, Angle Orthodontist 24:193-213, 1954.

3. AHLGREN, J.: Kinesiology of the Mandible: An EMG Study, Acta Odont Scand 25: $593-611,1967$.

4. AHLGREN, J.: The Silent Period in the EMG of the Jaw Muscles During Mastication and its Relationship to Tooth Contact, Acta Odont Scand 27:219-227, 1969.

5. BRENMAN, H. S.; BLACK, M. A.; and COSLET, J. G.: Interrelationship Between the Electromyographic Silent Period and Dental Occlusion, J Dent Res 27:502, 1968.

6. BESSETTE, R.; BISHOP, B.; and MOHL, N.: Duration of Masseteric Silent Period in Patients with TMJ Syndrome, $J$ Appl Physiol 30:864-869, 1971.

7. WIDMALM, S. E.: The Silent Period in the Masseter Muscle of Patients with TMJ Dysfunction, Acta Odont Scand 34:43-52, 1976.

8. BAILEY, J. O., JR.: The Electromyographic Silent Period in Normal Subjects and Patients with TMJ-Muscle-Pain Dysfunction, M. S. Thesis, University of Michigan, 1976.
9. BAILEY, J. O., JR.; MCCALL, W. D., JR.; and ASH, M. M., JR.: Electromyographic Silent Periods and Jaw Motion Parameters: Quantitative Measures of Temporomandibular Joint Dysfunction, $J$ Dent Res 56:249-253, 1977.

10. BAILEY, J. O., JR.; MCCALL, W. D., JR.; and ASH, M. M., JR.: The Influence of Mechanical Input Parameters on the Duration of the Mandibular Joint Electromyographic Silent Period in Man, Arch Oral Biol 22: 619-623, 1977.

11. MCCALL, W. D., JR.; UTHMAN, A. A.; and MOHL, N. D.: TMJ Symptom Severity and EMG Silent Periods, $J$ Dent Res 57:709-714, 1978.

12. MATTHEWS, B. and YEMM, R.: A Silent Period in the Masseter Electromyogram Following Tooth Contact in Subjects Wearing Full Dentures, Arch Oral Biol 15:531-535, 1970.

13. NAGASAWA, T.; SASAKI, T.; and TSURU, H.: Masseteric Silent Period After Tooth Contact in Full Denture Wearers, $J$ Dent Res $55: 314,1976$.

14. WILDMALM, S. E.: Tooth Tapping Ability of Young and Elderly Males and Females, $J$ Oral Rehab 4:169-180, 1977.

15. ÖWALL, B. and ELMQVIST, D.: Motor Pauses in EMG Activity During Chewing and Biting, Odont Rev 26:17-38, 1975.

16. ÖWALL, B.: Masseter Motor Pause Frequency in Full Denture Wearers as Related to Different Food Textures, Swed Dent $J$ 1:15-18, 1977.

17. MCNAMARA, D. C.; CRANE, P. F.; MCCALL, W. D., JR.; and ASH, M. M., JR.: Duration of the Electromyographic Silent Period Following the Jaw Jerk Reflex in Human Subjects, $J$ Dent Res 56:660-664, 1977.

18. BESSETTE, R. W.; DUDA, L.; MOHL, N. D.; and BISHOP, B.: Effect of Biting Force on the Duration of the Masseteric Silent Period, $J$ Dent Res 52:426-430, 1973.

19. BAILEY, J. O., JR.; MCCALL, W. D., JR.; MANSOUR, N. N.; and ASH, M. M., JR:: The Role of Cutaneous Receptors in the Menton Tap Silent Period, $J$ Dent Res, Accepted for publication.

20. REYNOLDS, J. M. and THEXTON, A. J.: The Effect Upon Masseteric Electromyogram of Double Mechanical Stimuli to Teeth, $J$ Physiol $275: 65 \mathrm{P}, 1978$.

21. WATT, D. M.; TURNBULL, J. R.; SABERI, M.; BEYLI, M. S.; and AGUILAR, E.: The Influence of Percussion, Occlusion, and Mastication on the Occurrence of Silent Periods in Masseter Muscle Activity, $J$ Oral Rehab 3:371-385, 1976.

22. TALLGREN, A.; MCCALL, W. D., JR.; WALKER, G. F.; and LANG, B. R.: Longitudinal Study of Jaw Muscles and 
Facial Morphology in Denture Wearers, IADR Progr \& Abst 55:100, 1976.

23. SIEGAL, S.: Nonparametric Statistics for the Behavioral Sciences. New York: McGraw-Hill, 1956.

24. WINER, B. J.: Statistical Principles in Experimental Design, 2nd ed. New York: McGraw-Hill, 1971.

25. GEISTER, D. E.; MCCALL, W. D., JR.; and ASH, M. M., IR.: Computerized Data Acquisition and Analysis for Real Time Electromyography in Clinical Dentistry, Proc IEEE 63:1404-1414, 1975.

26. ALTUG, S. S.; CHILDRESS, C. T., JR.; DEMUND, S. M.; MCCALL, W. D., JR.; and ASH, M. M., JR.: An Interactive Computer Peripheral to Measure the Electromyographic Silent Period, IEEE Trans, Biomed Engr BME-23:160-164, 1976.

27. SCHWARZE, K. D.; MCCALL, W. D., JR, TALLGREN, A.; and ASH, M. M., JR.: Measurement of EMG Silent Period Duration by Digital Computet, IADR Progr \& Abst 56:717, 1977.

28. GOLDBERG, L. J.: The Effect of Jaw Position on the Excitability of Two Reflexes Involving the Masseter Muscle in Man, Archs Oral Biol 17:565-576, 1972.

29. HANNAM, A. G.: Effect of Voluntary Contraction of the Masseter and Other Muscles upon the Masseteric Reflex in Man, $J$ Neurol Neurosurg Psychiat 35:66-71, 1972.
30. MANSOUR, N. N.: A Self-consistent Method for Measuring Electromyographic Silent Periods, M. S. Thesis, University of Michigan, 1978.

31. BRATZLAVSKY, M.: Pauses in Activity of Human Jaw Closing Muscles, Exp Neurol 36:160-165, 1972 .

32. YU, S.-K. J.; SCHMITT, A.; and SESSLE, B. J.: Inhibitory Effects on Jaw Muscle Activity of Innocuous and Noxious Stimulation of Facial and Intraoral Sites in Man, Arch Oral Biol 18:861-870, 1973.

33. WIDMALM, S.-E. and HEDEGARD, B.: Reflex Activity in the Masseter Muscle of Young Individuals. I. Experimental Procedures -- Results, J Oral Rehab 3:4 1-55, 1976. II. Discussion and references, I Oral Rehab 3:167-180, 1976 .

34. TALLGREN, A.; WALKER, G. F.; HOLDEN, S.; and ASH, M. M., JR.: The Effect of Denture Wearing on Facial Morphology and Jaw Muscle Activity, IADR Progr \& Abst $56: 167,1977$.

35. TALLGREN, A.; LANG, B. R.; WALKER, G. F.; and ASH, M. M., JR.: Roentgen Cephalometric Analysis of Ridge Resorption and Changes in Jaw and Occlusal Relationships in Immediate Complete Denture Wearers, $J$ Oral Rehab, Accepted for publication.

\section{BULLETIN}

Due to contractual problems beyond our control, the American Association for Dental Research has changed the dates for its 1980 meeting. The new dates are March $20-23,1980$. The meeting will still be held at the Hotel Bonaventure in Los Angeles, California. Only the dates have been changed. Please note the new date on your calendar and adjust your travel plans accordingly. Details on the meeting and registration information are forthcoming. 